\title{
Biomass production by Arthrospira platensis under different culture conditions
}

\author{
Gabriela Fernandes Pepe da Silva de CASTRO ${ }^{1 *}$, Roberta Ferreira RIZZO ${ }^{1}$, Thaís Souza PASSOS ${ }^{1}$, \\ Beatriz Nascimento Corrêa dos SANTOS $^{1}$, Daiana da Silva DIAS ${ }^{1}$, Josiane Roberto DOMINGUES ${ }^{1}$, \\ Kátia Gomes de Lima ARAÚJO ${ }^{1}$
}

\begin{abstract}
In biotechnological processes, the culture media components are responsible for high costs and exert a strong influence on the cyanobacteria behavior. The objective of this study was to evaluate the Arthrospira platensis growth potential for biomass production under different cultivation conditions using an experimental design. Three factors that are important for cyanobacteria growth were evaluated: sodium bicarbonate ( 9 to $18 \mathrm{~g} / \mathrm{l}$ ), sodium nitrate $(1.25$ to $2.5 \mathrm{~g} / \mathrm{l})$, and irradiance (20 to $120 \mu \mathrm{mol}$ photons/ $\mathrm{m}^{2} \cdot \mathrm{s}^{-1}$ ). The results showed that the concentration of $\mathrm{NaNO}_{3}$ in the A. platensis medium can be reduced, resulting in increased concentrations of biomass produced. There was a higher biomass production due to the increase in the concentration of $\mathrm{NaHCO}_{3}$ and irradiance, mainly when these two factors varied tending towards the highest values studied. The results demonstrate the potential to produce Arthrospira platensis with lower costs and effluent generation without affecting cultivation performance.
\end{abstract}

Keywords: cyanobacteria; culture medium; sodium bicarbonate; sodium nitrate; irradiance.

\section{Introduction}

Cyanobacteria are a diverse group of prokaryotic microorganisms that carry out photosynthesis by oxygen evolution using a mechanism very similar to that used by higher plants. They have high morphological, physiological, and structural diversity necessary to adapt to a wide range of environmental parameters (Mundt et al., 2001). In this group of microorganisms, photosynthesis has been considered as an effective way to reduce atmospheric carbon dioxide (Yun \& Park, 1997) and to produce compounds of high economic and scientific value (Jeon et al., 2005).

Over 70\% of marketing of Arthrospira, under the trade name of Spirulina, is for human consumption, mainly as a healthy food. Current interest in this microorganism is due to the content of protein, essential amino acids, minerals, vitamins and essential fatty acids. It contains about $60-70 \%$ protein and is rich in vitamins such as $B_{12}$ and provitamin $A$ ( $\beta$-carotene) and minerals such as iron. In addition, it is one of the few sources of $\gamma$-linolenic acid. These cyanobacteria are commercially produced in large outdoor ponds under controlled conditions or they can grow naturally in alcaline lakes (Koru, 2012).

Pollution of groundwater by nitrates has become a problem that affects all countries, regardless of their level of development. It reduces the potential of available freshwater resources, causes sanitation problems, especially in rural areas, and hinders the socioeconomic development of the country. Many studies have shown that anthropogenic activities involving nitrogenous compounds such as mineral fertilizers, products of organic agriculture, septic tanks, and manure are the main factors leading to the increase of nitrate pollution (Tagma et al., 2009). However, discarding Zarrouk medium with nitrate can also be a source of environmental contamination, and a way to reduce its dumping into natural areas would be the use of culture media with lower concentrations of nitrate since it does not affect the biomass yield.

In biotechnological processes, the culture media components are responsible for high costs and exert a strong influence on the microorganism behavior. Several studies have been carried out aiming at reducing these costs by using alternative components or changing their concentration. Zarrouk is the standard culture medium used for cyanobacterium Arthrospira platensis. Some examples of an alternative means of cultivation are the replacement of sodium nitrate with other sources of nitrogen such as urea and/or potassium nitrate (Godoy Danesi et al., 2011), addition of organic substrates (Andrade \& Costa, 2009), use of fertilizers or seawater with and without enrichment of $\mathrm{NaHCO}_{3}$ and $\mathrm{NaNO}_{3}$ (Gami et al., 2011), and use of swine wastewater (Mezzomo et al., 2010).

This study evaluated the growth potential of cyanobacterium Arthrospira platensis for biomass production under different cultivation conditions using an experimental design.

\section{Materials and methods}

\subsection{Microorganism}

The cyanobacterium A. platensis was obtained from the Department of Marine Biology at the "Universidade Federal Fluminense". The starter cultures were prepared by inoculating A. platensis in modified Zarrouk medium (Zarrouk, 1966) at $30^{\circ} \mathrm{C}$, under agitation with $0.75 \mathrm{vvm}$ of air supply and constant irradiance of $20 \mu \mathrm{mol}$ photons $/ \mathrm{m}^{2} \cdot \mathrm{s}^{-1}$. The cultivations were 
performed using modified Zarrouk medium varying sodium nitrate and sodium bicarbonate concentrations and irradiance using a $2^{3}$ full-factorial central composite rotational design (CCRD) with 6 axial points $(\alpha=1,68)$ and 3 replicates at the center point, totaling 17 experiments (Rodrigues \& Iemma, 2009), as described in Table 1.

The cultivations were performed in a growth chamber in transparent glass bottles of 11 containing $500 \mathrm{ml}$ of sterilized Zarrouk medium. Cell counts were performed every 3 days until reaching stationary phase. The cell culture experiments were performed under the following conditions: agitation with $0.75 \mathrm{vvm}$ of air supply, room temperature, and continuous lighting, according to each experiment. All flasks were inoculated with standardized cyanobacterium $(0.05 \mathrm{mg} / \mathrm{ml})$, and the optical density was read at $750 \mathrm{~nm}$ and correlated with a calibration curve (Lourenço, 2006).

\subsection{Biomass production}

Cellular growth was measured by following apparent turbidity at $750 \mathrm{~nm}$ (optical density - OD) (Magalhães et al., 2004). The cell culture was centrifuged at $8,000 \mathrm{rpm}$ for $30 \mathrm{~min}$ at $5^{\circ} \mathrm{C}$ (Centrifuge 5403, Eppendorf, New York, USA) to separate the biomass from the modified Zarrouk medium and was recentrifuged in distilled water to remove all traces of culture medium. Concentration was determined based on the optical density measured at a wavelength of $750 \mathrm{~nm}$ by a spectrophotometer (UV-2600; Shimadzu, Tokyo, Japan). A standard curve suggested good linear relationship between turbidity and cell number (Biomass $(\mathrm{mg} / \mathrm{l})=1.3578 \mathrm{OD}_{750 \mathrm{~nm}}$ - 0.0308; $\mathrm{R}^{2}=0,9884$ ). At this wavelength, there is no light absorption by any pigment; therefore, reading will correspond only to the scattering of light (Silva et al., 2009).

The biomass produced under the conditions that promoted the best and worst growth, was evaluated in terms of protein content and phycobiliproteins. The biomass total protein concentration was determined by the Kjeldahl method (Instituto Adolfo Lutz, 2008). The nitrogen concentration was converted to protein using the conversion factor 6.5 . The results were expressed as $\mathrm{mg} \%$ protein in the biomass.

The extracts containing the pigments were obtained by aqueous extraction from the biomass using a method that was standardized in our laboratory. A. platensis biomass was subjected to three freeze/thaw cycles to allow leakage of intracellular contents. The extraction was carried out with distilled water and centrifugation at $8,000 \mathrm{rpm}$ for $20 \mathrm{~min}$ at $25^{\circ} \mathrm{C}$ (Sigma, 3K 30 Centrifuge, Newtown, North Shropshire), followed by filtration through a qualitative filter paper.

Table 1. Experimental variables and growth parameters for A. platensis.

\begin{tabular}{lccccc}
\hline \multicolumn{1}{c}{ Parameters } & $-\alpha$ & -1 & 0 & 1 & $\alpha$ \\
\hline Sodium bicarbonate $(\mathrm{g} / \mathrm{l})$ & 9 & 10.82 & 13.5 & 16.18 & 18 \\
Sodium nitrate $(\mathrm{g} / \mathrm{l})$ & 1.25 & 1.5 & 1.875 & 2.25 & 2.5 \\
Irradiance & 20 & 28.33 & 70 & 111.67 & 120 \\
$\left(\mu \mathrm{mol}\right.$ photons $\left./ \mathrm{m}^{2} . \mathrm{s}^{-1}\right)$ & & & & & \\
\hline
\end{tabular}

The phycocyanin and allophycocyanin in the extracts were determined by absorbance measurements at 620 and $650 \mathrm{~nm}$ on a spectrophotometer (Shimadzu, UV-2600, Tokyo, Japan) and using the equations developed by Bryant, as described by Chapman and Kremer (1988), Equations 1 and 2, respectively, after subtracting optical density at $750 \mathrm{~nm}$ to correct for residual scattering (Silva et al., 2009). The results were expressed as $\mathrm{mg} \%$ phycobiliprotein in the biomass.

$$
\begin{aligned}
& \operatorname{Phycocianin}(\mathrm{mg} / \mathrm{ml})=\frac{\left\{\mathrm{A}_{620}-\left(0,72 \times \mathrm{A}_{650}\right)\right\}}{6,29} \\
& \operatorname{Alophycocianin}(\mathrm{mg} / \mathrm{ml})=\frac{\left\{\mathrm{A}_{650}-\left(0,191 \times \mathrm{A}_{620}\right)\right\}}{5,79}
\end{aligned}
$$

\section{Results and discussion}

The growth curves showed that the different culture conditions used influenced the biomass production after 21 days of culture, ranging from $1,000 \mathrm{mg} / \mathrm{L}$ (experiment 4 ) to 3,270 $\mathrm{mg} / \mathrm{L}$ (experiment 6). The experiments with higher biomass production were number 6,5 , and 14 , with 3,$270 ; 2,380$; and 2,240 $\mathrm{mg} / \mathrm{L}$, respectively, and experiments 4,3 , and 1 had the lowest growth rates, 1,$000 ; 1,060$; and $1,070 \mathrm{mg} / \mathrm{L}$, respectively, on the $21^{\text {th }}$ day of culture (Figure 1 and Table 2). At the end of the cultivation time, the average temperature and $\mathrm{pH}$ of the studied conditions were $27.89 \pm 1.09^{\circ} \mathrm{C}$ and $10.61 \pm 0.19$, respectively.

As can be seen in Figure 1, some experimental conditions influenced the time at which the culture reached stationary phase; it started after 12 days of cultivation for experiment 14, but apparently it not start before 21 days for experiment 6 , which shows that changes in the medium composition influenced the metabolism and growth of cyanobacteria.

Since the production of biomass was the greatest after 21 days of culture, protein and phycobiliprotein were determined in the biomass collected at that time. For the same reason, the effect of the studied variables on the biomass, protein, and phycobiliprotein was statistically evaluated based on the data obtained at that time. The statistical analysis of the different experimental conditions of used in the design (17 experiments) show that irradiance was

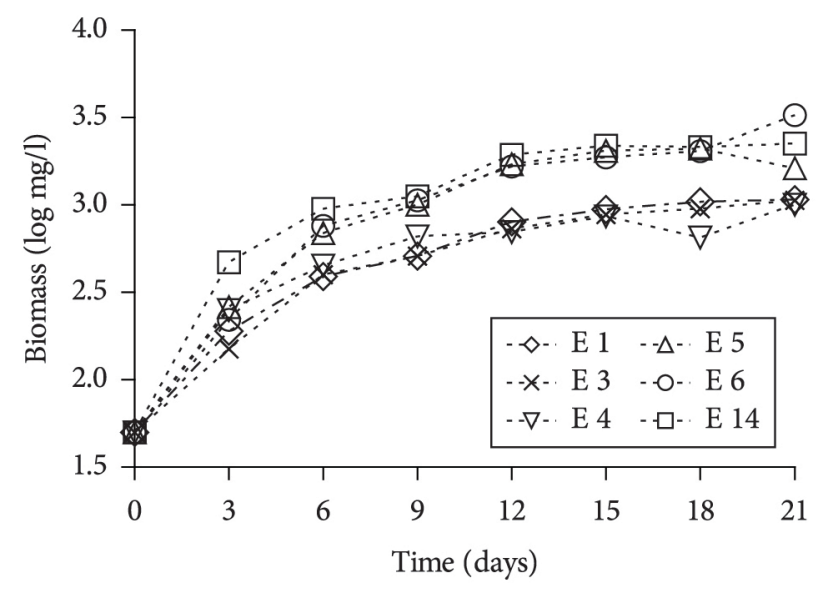

Figure 1. A. platensis biomass production during 21 days. 
the variable that most influenced the biomass production on the first days of culture (after 3, 6, and 9 days), and production was greater under higher irradiance. On the other hand, during the last days of culture, the concentration of sodium bicarbonate in the culture medium was the parameter that most influenced biomass production from $A$. platensis.

The value $\mathrm{p}<0.1$ was used due to the variability inherent in biological processes, according to Rodrigues \& Iemma (2009). In this case, there was a significant effect of the sodium bicarbonate concentration. However, the quadratic model used was not satisfactory since the determination coefficient $\left(\mathrm{R}^{2}\right)$ found was quite low, approximately 0.5259 . Thus, given the inadequacy of quadratic model tested, the axial points shown in Table 2 it were excluded, for statistical analysis purposes, and a linear model adequacy was tested. The following results were obtained taking these facts into consideration.

The regression coefficients shown in Table 3 were calculated; the effects of independent linear terms $\mathrm{NaHCO}_{3}, \mathrm{NaNO}_{3}$ and irradiance and the combination of terms $\mathrm{NaNO}_{3}$ and irradiance were statistically significant for biomass production, at a significance level of $10 \%(\mathrm{p}<0.1)$.

Thus, Equation 3 shown below gives the production of biomass predicted by the model based on encoded variables, considering only the statistically significant terms in Table 3 $(\mathrm{p}<0.1)$.

Biomass $(\mathrm{mg} / 1)=1859.1+667.5 \mathrm{NaHCO}_{3}-$

$230 \mathrm{NaNO}_{3}+155$ Irradiance $-185 \mathrm{NaNO}_{3}$ Irradiance

Table 4 shows the analysis of variance (ANOVA) for A. platensis biomass production, applied to test the model significance determined by Equation 3. Analysis of variance showed explained variation of $96.46 \%\left(R^{2}=0.9646\right)$, and the $\mathrm{F}$ value obtained was much higher than the reference value. The $\mathrm{R}^{2}$ value suggests that this model is suitable to describe the behavior of $A$. platensis growth towards variations in $\mathrm{NaHCO}_{3}$ and $\mathrm{NaNO}_{3}$ concentrations and irradiance.

Therefore, it was found that, under the experimental conditions studied, biomass production tended to increase with an increase in the $\mathrm{NaHCO}_{3}$ concentration in the medium and increased irradiance. However, the results also indicated that biomass concentration was higher when $\mathrm{NaNO}_{3}$ concentration in the medium decreased, which shows that the commonly used concentration in the Zarrouk medium can be overestimated, indicating that this is not the most suitable medium for A. platensis growth.

Table 2. Experimental variables and A. platensis biomass production results (21 days of cultivation).

\begin{tabular}{|c|c|c|c|c|c|}
\hline Experiment (E) & $\begin{array}{l}\text { Sodium bicarbonate } \\
(\mathrm{g} / \mathrm{l})\end{array}$ & Sodium nitrate $(\mathrm{g} / \mathrm{l})$ & $\begin{array}{c}\text { Irradiance } \\
\left(\mu \mathrm{mol} \text { photons } / \mathrm{m}^{2} \cdot \mathrm{s}^{-1}\right)\end{array}$ & $\begin{array}{l}\text { Biomass production } \\
(\mathrm{mg} / \mathrm{l})\end{array}$ & $\begin{array}{c}\text { Productivity } \\
\text { (mg/l/day) } \\
\mathrm{P}_{21}\end{array}$ \\
\hline 1 & 10.82 & 1.500 & 28.33 & 1,070 & 48.571 \\
\hline 2 & 16.18 & 1.500 & 28.33 & 1,540 & 70.952 \\
\hline 3 & 10.82 & 2.250 & 28.33 & 1,060 & 48.095 \\
\hline 4 & 16.18 & 2.250 & 28.33 & 1,000 & 45.238 \\
\hline 5 & 10.82 & 1.500 & 111.67 & 2,380 & 110.952 \\
\hline 6 & 16.18 & 1.500 & 111.67 & 3,270 & 153.333 \\
\hline 7 & 10.82 & 2.250 & 111.67 & 2,210 & 102.857 \\
\hline 8 & 16.18 & 2.250 & 111.67 & 2,150 & 100.000 \\
\hline 9 & 9.00 & 1.875 & 70.00 & 2,050 & 95.238 \\
\hline 10 & 18.00 & 1.875 & 70.00 & 1,625 & 75.000 \\
\hline 11 & 13.50 & 1.250 & 70.00 & 1,980 & 91.905 \\
\hline 12 & 13.50 & 2.500 & 70.00 & 1,910 & 88.571 \\
\hline 13 & 13.50 & 1.875 & 20.00 & 1,390 & 63.809 \\
\hline 14 & 13.50 & 1.875 & 120.00 & 2,240 & 104.286 \\
\hline 15 & 13.50 & 1.875 & 70.00 & 1,790 & 82.857 \\
\hline 16 & 13.50 & 1.875 & 70.00 & 1,930 & 89.524 \\
\hline 17 & 13.50 & 1.875 & 70.00 & 2,050 & 95.238 \\
\hline
\end{tabular}

Table 3. Regression coefficients for A. platensis biomass production after 21 days of cultivation.

\begin{tabular}{|c|c|c|c|c|c|c|}
\hline \multirow{2}{*}{ Factors } & \multirow{2}{*}{$\begin{array}{l}\text { Regression } \\
\text { coefficients }\end{array}$} & \multirow{2}{*}{ Standard error } & \multirow{2}{*}{$\mathrm{t}(2)$} & \multirow{2}{*}{$\mathrm{p}$-value } & \multicolumn{2}{|c|}{ Estimates interval (90\%) } \\
\hline & & & & & Lower limit & Upper limit \\
\hline Average & 1859.09 & 39.24 & 47.38 & 0.00 & 1744.52 & 1973.66 \\
\hline $\mathrm{NaHCO}_{3}$ & 667.50 & 46.01 & 14.51 & 0.00 & 533.16 & 801.84 \\
\hline $\mathrm{NaNO}_{3}$ & -230.00 & 46.01 & -5.00 & 0.04 & -364.34 & -95.66 \\
\hline Irradiance & 155.00 & 46.01 & 3.37 & 0.08 & 20.66 & 289.34 \\
\hline $\mathrm{NaNO}_{3} /$ Irradiance & -185.00 & 46.01 & -4.02 & 0.06 & -319.34 & -50.66 \\
\hline
\end{tabular}


Figure 2 shows the response surfaces for A. platensis biomass production after 21 days of cultivation based on the variables determined by mathematical model described in Equation 3. Biomass production increased due to the higher concentration of $\mathrm{NaHCO}_{3}$ and higher irradiance, especially when these two factors varied tending towards the highest values studied. However, when higher sodium bicarbonate concentrations were used, even at lower light intensity, there was an increase in biomass production confirming that $\mathrm{NaHCO}_{3}$ was the factor with greatest influence on biomass production, which tended to decrease due to an increase in $\mathrm{NaNO}_{3}$ concentration, within the concentration range studied.
Experiment 6, $16.18 \mathrm{~g} / \mathrm{l}$ of $\mathrm{NaHCO}_{3}$ (close to the value used in Zarrouk medium of $18 \mathrm{~g} / \mathrm{l})$, high irradiance $(111.67 \mu \mathrm{mol}$ photons $\left./ \mathrm{m}^{2} . \mathrm{s}^{-1}\right)$, and low $\mathrm{NaNO}_{3}$ concentration $(1.5 \mathrm{~g} / \mathrm{l})$, had the highest biomass production among all tested conditions.

Productivity and efficiency of light utilization are functions of cell density. Selecting the optimal cell concentration is crucial for an efficient $\mathrm{CO}_{2}$ sequestration. Even with optimum cell concentration, not all light energy is captured by cells, whereas at higher concentrations, a greater proportion of cells are in dark due to self-shading. In aqueous environment, the dissolved $\mathrm{CO}_{2}$ is in equilibrium with $\mathrm{H}_{2} \mathrm{CO}_{3}, \mathrm{HCO}_{3}^{-}$and $\mathrm{CO}_{3}^{-2}$, whose concentration depends on $\mathrm{pH}$ and temperature. Due to rapid

Table 4. ANOVA evaluation of $A$. platensis biomass production after 21 days of cultivation.

\begin{tabular}{|c|c|c|c|c|c|}
\hline Source of variation & Sum of squares & Degrees of freedom & Mean square & F calc & p-value \\
\hline Regression & 4334.09 & 4 & 1083.52 & 22.42 & $<0.1$ \\
\hline Residual & 290.00 & 6 & 48.33 & & \\
\hline Total & 4624.09 & 10 & 320.50 & & \\
\hline
\end{tabular}

$\%$ Explained variation $\left(\mathrm{R}^{2}\right)=96.46 \% \mathrm{~F}=3.18$.
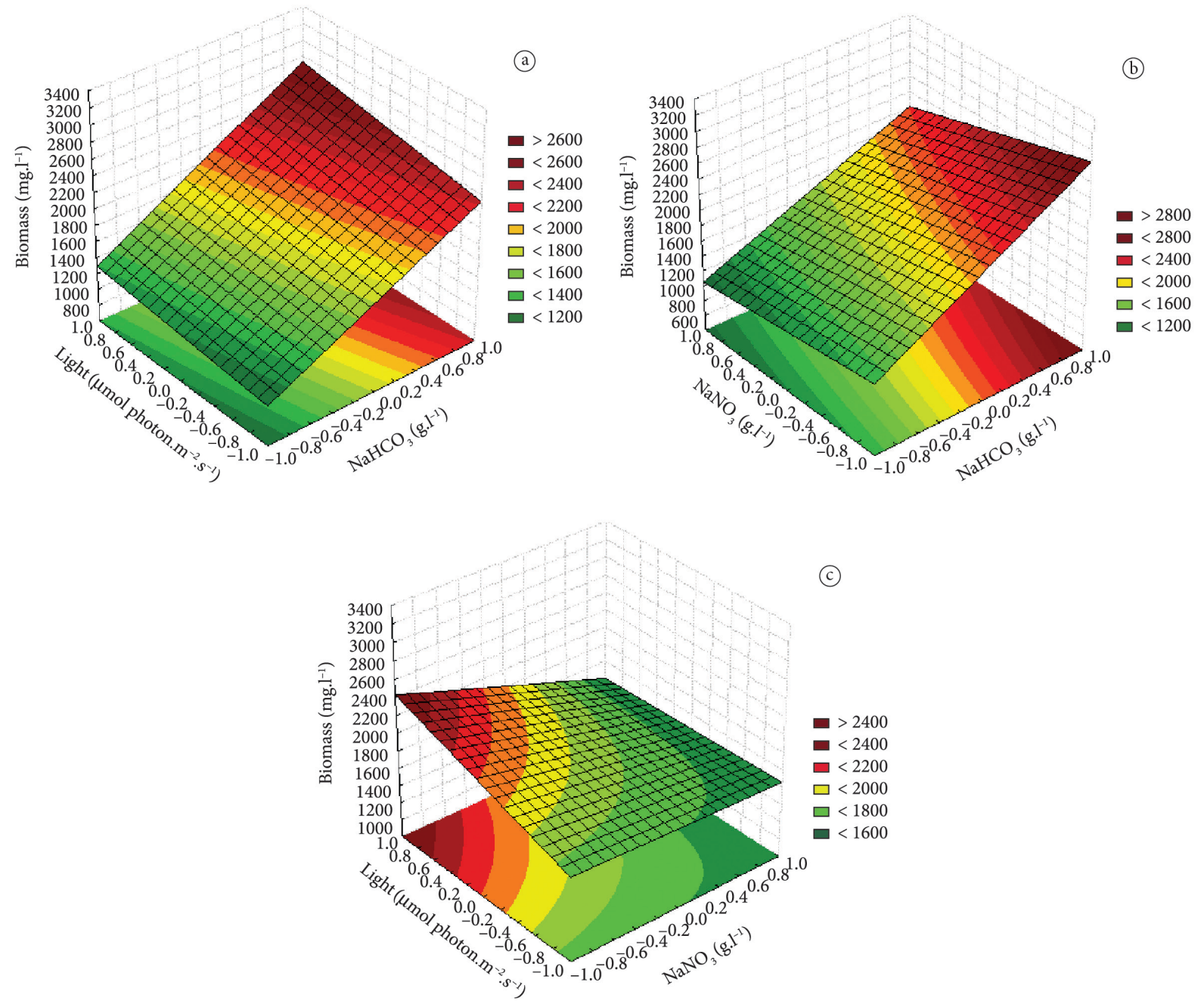

Figure 2. Response surface for A. platensis biomass production after 21 days of cultivation as a function of (a) irradiance and $\mathrm{NaHCO}_{3}$ concentration; (b) $\mathrm{NaNO}_{3}$ and $\mathrm{NaHCO}_{3}$ concentrations; (c) irradiance and $\mathrm{NaNO}_{3}$ concentration. 
transformation between them, the use of any inorganic carbon will not affect the equilibrium. Cyanobacteria cells prefer to capture $\mathrm{HCO}_{3}{ }^{-}$rather than $\mathrm{CO}_{2}$ although that is a poorer carbon source. The biomass productivity increased with an increase in $\mathrm{CO}_{2}$ in the gas mixture up to a certain percentage, after which, the productivity decreased (Kumar et al., 2011). This preference for bicarbonate favored the continuous growth of cyanobacteria, even with higher cell density in the last days of culture, which favors the cultivation conditions used in this study, with higher bicarbonate concentrations in the medium composition.

The nitrogen assimilated by cyanobacteria is used primarily for cell growth, and its excess is stored as organic compounds, such as proteins (Rodrigues et al., 2010). This possibility of storing nitrogen allows this group of microorganisms to grow with small amounts of mineral. Several authors used alternative sources of nitrogen and at lower concentrations compared to that of the Zarrouk medium, and they found that it is possible to cultivate the genus Arthrospira in these media without affecting the growth rate and the content of interest compounds (dry biomass, protein, phycobiliproteins, and others (Colla et al., 2007; El-Baky et al., 2008), which is in agreement with the results of the present study regarding the A. platensis growth with lower $\mathrm{NaNO}_{3}$ concentration in the medium.

The nitrate salts $\mathrm{NaNO}_{3}$ and $\mathrm{KNO}_{3}$ are the sources of nitrogen that lead to higher biomass production, justifying its application in culture media such as Paoletti, Zarrouk, and Schlosser (Sassano et al., 2007). According to Colla et al. (2007), maintaining the culture at $30^{\circ} \mathrm{C}$, the productivity of $A$. platensis was not affected under varying concentrations of sodium nitrate within the range of 0.625 to $2.5 \mathrm{~g} / \mathrm{l}$; this result was also reported by El-Baky et al. (2008). These results demonstrate that the amount of this compound can be reduced by approximately $25 \%$ of the Zarrouk medium concentration $(2.5 \mathrm{~g} / \mathrm{l})$ without loss of biomass production. In the present study, it was possible to reduce of the nitrate concentration $(1.5 \mathrm{~g} / \mathrm{l})$ in $A$. platensis culture medium to $60 \%$. Biomass production increased with the reduction of $\mathrm{NaNO}_{3}$ concentration in the medium in experiment 6 . This can be explained by other factors that were varied in this study, such as sodium bicarbonate and irradiance. In experiment 6 , for example, the highest values of bicarbonate and irradiance, which are important parameters for cyanobacteria growth, were tested.

Moreira et al. (2012) conducted a study to assess the production of biomass in S. platensis using different conditions of stirring, nitrogen source, amount of micronutrients, and luminosity. The results showed that the maximum production of biomass $(2.70 \mathrm{~g} / \mathrm{l})$ was obtained under the following conditions for 15 days: luminosity $15 \mathrm{~W}$ (highest level tested), stirring $120 \mathrm{rpm}$, source of nitrogen $1.5 \mathrm{~g} / \mathrm{l}$ (lowest level tested) and micronutrients $0.75 \mathrm{ml} / \mathrm{L}$.
However, Celekli et al. (2009) demonstrated that $2.5 \mathrm{~g} / \mathrm{l}$ of sodium nitrate produced the better growth rate of $A$. platensis than the concentration of $2.0 \mathrm{~g} / \mathrm{l}$. El-Baky et al. (2008) reported that the use of $1.875 \mathrm{~g} / \mathrm{l}$ of sodium nitrate, while maintaining the culture at $35^{\circ} \mathrm{C}$, decreases $A$. maxima biomass production but confers higher concentrations of proteins, lipids, and phenolic compounds. However, these results were obtained varying the concentration of nitrate without simultaneous variation of bicarbonate and irradiance, unlike the experimental conditions used in the present study, in which 3 simultaneous parameters, which are important for cyanobacteria growth as sources of carbon, nitrogen, and irradiance, varied simultaneously.

Madkour et al. (2012) proposed means to reduce the cost of Zarrouk medium containing superphosphate, commercial sodium bicarbonate, potassium chloride, and crude sea salt by using 10, 20,30, and $40 \%$ of nitrogen concentration in the Zarrouk medium, obtained using ammonium nitrate or urea. The maximum biomass, chlorophyll, and protein production was obtained in the medium with $30 \%$ ammonium nitrate $(0.813 \pm 0.018 \mathrm{~g} / \mathrm{l}, 0.0685 \pm 0.0024 \mathrm{mg} / \mathrm{L}$ and $52.62 \%)$, values similar to those found in Zarrouk medium. These values were lower than the maximum biomass production observed in the present study (experiment 4), and the lowest concentration of biomass was obtained with 1,000 mg/L after 21 days of culture.

Table 5 shows the differences of total protein content and production of phycocyanin and allophycocyanin in relation to biomass production by $A$. platensis between the experiments with the highest and lowest biomass production (3.270 and $1.000 \mathrm{mg} / \mathrm{L}$ ), after 21 days of culture. During the cyanobacterium culture, these parameters either increased or did not change, depending on the culture conditions; however, there was no significant effect on the $\mathrm{NaHCO}_{3}$ and $\mathrm{NaNO}_{3}$ concentrations and irradiance. In the experiment with the highest biomass concentration, experiment 6 , showed lower contents of total protein, phycocyanin and allophycocyanin than those of experiment 4. In experiment 6 , it was used higher irradiance and lower nitrate concentration, but the same concentration of bicarbonate in culture medium used in experiment 4 . This explains why there was greater biomass production in experiment 6 and higher content of phycobiliproteins in experiment 4 .

The effects of irradiance, with and without reflector light (RL) and two nitrogen sources $\left(\mathrm{KNO}_{3}\right.$ or urea) on biomass production amino acid and the content of phycobiliproteins of $S$. platensis were evaluated. The maximum biomass yield was 6,900 and $6,100 \mathrm{mg} / \mathrm{L}$ with $\mathrm{RL}+$ urea and $\mathrm{RL}+\mathrm{KNO}_{3}$, respectively. The highest content of phycocyanin $(14.81 \pm 0.22 \%)$ and allophycocyanin $(4.52 \pm 0.09 \%)$ were obtained with 4 lux (Ajayan et al., 2012). These results indicate that biomass production was much higher than that found in this study, in

Table 5. Experimental variables, protein content, and production of phycocyanin and allophycocyanin in terms of biomass production by A. platensis for experiments 4 and 6 after 21 days of cultivation.

\begin{tabular}{ccccccc}
\hline E & $\begin{array}{c}\text { Sodium bicarbonate } \\
(\mathrm{g} / \mathrm{l})\end{array}$ & $\begin{array}{c}\text { Sodium nitrate } \\
(\mathrm{g} / \mathrm{l})\end{array}$ & $\begin{array}{c}\text { Irradiance }(\mu \mathrm{mol} \\
\left.\text { photons } / \mathrm{m}^{2} \cdot \mathrm{s}^{-1}\right)\end{array}$ & $\begin{array}{c}\text { Total protein } \\
(\%)\end{array}$ & $\begin{array}{c}\text { Phycocyanin } \\
\text { produced }(\%)\end{array}$ & $\begin{array}{c}\text { Allophycocyanin } \\
\text { produced }(\%)\end{array}$ \\
\hline 4 & 16.18 & 2.25 & 28.33 & 60.84 & 8.27 & 4.20 \\
6 & 16.18 & 1.5 & 111.67 & 46.19 & 7.35 & 2.95 \\
\hline
\end{tabular}


which the highest biomass yield was obtained in experiment 6 $(3.270 \mathrm{mg} / \mathrm{L})$. With regard to the analysis of phycobiliproteins in the present study, lower concentration of phycocyanin (8.27\%) was found, and the concentration of allophycocyanin (4.2\%) was close to that obtained in the experiment 4 in the present study. Zeng et al. (2012) investigated S. platensis cultivation in Zarrouk medium to increase $\mathrm{CO}_{2}$ fixation and phycocyanin production using conical flasks with $\mathrm{CO}_{2}$ and photobioreactors with $\mathrm{CO}_{2}$ and aeration. The maximum biomass concentration was $3,200 \mathrm{mg} / \mathrm{L}$ with an initial $\mathrm{pH} 9$, similar to that found on this study $(3,270 \mathrm{mg} / \mathrm{L}$ in experiment 6$)$. The maximum cell concentration in the aerated cultures was $5,960 \mathrm{mg} / \mathrm{L}$ under intermittent supply of $\mathrm{CO}_{2}(20 \mathrm{mM} / \mathrm{L}$ every 2 days $)$. The use of continuous spraying of $0.1 \mathrm{l} / \mathrm{min}$ of compressed air in combination with $\mathrm{CO}_{2}$ intermittently supplied into a photobioreactor resulted in biomass content of $5,920 \mathrm{mg} / \mathrm{L}$ and phycocyanin concentration of $17.9 \%$. Furthermore, by optimizing photobioreactor, the biomass content increased to $7,270 \mathrm{mg} / \mathrm{L}$, and the concentration of phycocyanin was $16.8 \%$, one of the highest values found in the literature for this protein pigment. In the present study, the maximum amount of phycocyanin obtained (experiment 4) was $8.27 \%$.

After studying the phycobiliproteins production for six species of the genus Arthrospira (A. laxissima SAG 256.80, A. maxima SAG 49.88 and SAG 84.79, A. platensis SAG 85.79, SAG 86.79 and SAG 257.80) in Zarrouk and $\mathrm{RM}_{6}$ media for 12 days, the latter was the one with the highest phycocyanin and allophycocyanin production in all species, except for A. platensis SAG 85.79. The $\mathrm{RM}_{6}$ is an alternative lower cost medium, with lower sodium bicarbonate concentration, $8.0 \mathrm{~g} / \mathrm{l}$, and the same amount of sodium nitrate of that of Zarrouk medium (Tarko et al., 2012). In this case, although $\mathrm{RM}_{6}$ medium has a better performance than Zarrouk medium for producing phycobiliproteins, both media had a concentration of pigments much lower than that found in the present study, which reached $8.27 \%$ of phycocyanin in experiment 4.

Cell growth, $\mathrm{CO}_{2}$ fixation rate, and phycocyanin production by $S$. platensis were investigated using different irradiations $\left(100,300,500,700,900,1,100\right.$, and $1,300 \mu \mathrm{mol}$ photons $\left./ \mathrm{m}^{2} . \mathrm{s}\right)$. As irradiance increased from 100 to $700 \mu \mathrm{mol}$ photons $/ \mathrm{m}^{2} . \mathrm{s}^{-1}$, the overall productivity of biomass, $\mathrm{CO}_{2}$ consumption rate, and maximal phycocyanin productivity increased to 740,1530 , and $110 \mathrm{mg} / \mathrm{L} / \mathrm{d}$, respectively, which is equivalent to a biomass production containing $14.86 \%$ of phycocyanin, which is higher than that obtained in the present study (Chen et al., 2013).

\section{Conclusions}

There was an increase in biomass production due to the increase in $\mathrm{NaHCO}_{3}$ concentration and irradiance, especially when these two factors varied tending towards the highest values studied. However, with higher sodium bicarbonate concentrations, even under smaller irradiances, high biomass concentration was obtained, indicating that sodium bicarbonate was the factor with greatest influence on biomass production. Varying sodium nitrate concentration in A. platensis culture medium had a significant influence on biomass production; thus, this micronutrient can be used at lower concentrations than those of Zarrouk medium to obtain higher biomass concentrations.

\section{References}

Ajayan, K. V., Selvaraju, M., \& Thirugnanamoorthy, K. (2012). Enrichment of chlorophyll and phycobiliproteins in Spirulina platensis by the use of reflector light and nitrogen sources: An in-vitro study. Biomass and Bioenergy, 47, 436-441. http://dx.doi.org/10.1016/j. biombioe.2012.09.012.

Andrade, M. R., \& Costa, J. A. V. (2009). Culture of microalga Spirulina platensis in alternative sources of nutrients. Ciência e Agrotecnologia, 32(5), 1551-1556. http://dx.doi.org/10.1590/S1413-70542008000500029.

Çelekli, A., Yavuzatmaca, M., \& Bozkurt, H. (2009). Modeling of biomass production by Spirulina platensis as function of phosphate concentrations and $\mathrm{pH}$ regimes. Bioresource Technology, 100(14), 3625-3629.

Chapman, D. J., \& Kremer, B. P. (1988). Experimental phycology: A laboratory manual (pp. 134-140). Cambridge: Cambridge University Press.

Chen, C. Y., Kao, P. C., Tsai, C. J., Lee, D. J., \& Chang, J. S. (2013). Engineering strategies for simultaneous enhancement of C-phycocyanin production and $\mathrm{CO} 2$ fixation with Spirulina platensis. Bioresource Technology, 145(145), 307-312. http://dx.doi.org/10.1016/j. biortech.2013.01.054. PMid:23664178

Colla, L. M., Oliveira Reinehr, C., Reichert, C., \& Costa, J. A. V. (2007). Production of biomass and nutraceutical compounds by Spirulina platensis under different temperature and nitrogen regimes. Bioresource Technology, 98(7), 1489-1493. http://dx.doi.org/10.1016/j. biortech.2005.09.030. PMid:17070035

El-Baky, H. H. A., El-Baz, F. K., \& El-Baroty, G. S. (2008). Characterization of nutraceutical compounds in blue green alga Spirulina maxima. Journal of Medicinal Plants Research, 2(10), 292-300.

Gami, B., Naik, A., \& Patel, B. (2011). Cultivation of Spirulina species in different liquid media. Journal of Algal Biomass Utilization, 2(3), 15-26.

Godoy Danesi, E. D., Oliveira Rangel-Yagui, C., Sato, S., \& Monteiro de Carvalho, J. C. (2011). Growth and content of spirulina platensis biomass chlorophyll cultivated at different values of light intensity and temperature using different nitrogen sources. Brazilian Journal of Microbiology, 42(1), 362-373. http://dx.doi.org/10.1590/S151783822011000100046. PMid:24031643

Instituto Adolfo Lutz - IAL. (2008). Métodos químicos e físicos para análise de alimentos (4th ed.). São Paulo: IAL.

Jeon, Y., Cho, C., \& Yun, Y. (2005). Measurement of microalgal photosynthetic activity depending on light intensity and quality. Biochemical Engineering Journal, 27(2), 127-131. http://dx.doi. org/10.1016/j.bej.2005.08.017.

Koru, E. (2012). Earth food Spirulina (Arthrospira): production and quality standarts. In Y. El-Samragy (Ed.), Food additive (pp. 191203). Rijeka: InTech. http://dx.doi.org/10.5772/31848.

Kumar, K., Dasgupta, C. N., Nayak, B., Lindblad, P., \& Das, D. (2011). Development of suitable photobioreactors for CO2 sequestration addressing global warming using green algae and cyanobacteria. Bioresource Technology, 102(8), 4945-4953. http://dx.doi.org/10.1016/j. biortech.2011.01.054. PMid:21334885

Lourenço, S. O. (2006). Cultivo de microalgas marinhas: princípios e aplicações (1st ed.). São Carlos: RiMa.

Madkour, F. F., Kamil, A. E., \& Nasr, H. S. (2012). Production and nutritive value of Spirulina platensis in reduced cost media. Egyptian 
Journal of Aquatic Research, 38(1), 51-57. http://dx.doi.org/10.1016/j. ejar.2012.09.003.

Magalhães, C. C. P., Cardoso, D., Santos, C. P., \& Chaloub, R. M. (2004). Physiological and photosynthetic responses of Synechocystis aquatilis f. aquatilis (Cyanophyceae) to elevated levels of zinc. Journal of Phycology, 40(3), 496-504. http://dx.doi.org/10.1111/j.15298817.2004.03094.x.

Mezzomo, N., Saggiorato, A. G., Siebert, R., Tatsch, P. O., Lago, M. C., Hemkemeier, M., Costa, J. A. V., Bertolin, T. E., \& Colla, L. M. (2010). Cultivation of microalgae Spirulina platensis (Arthrospira platensis) from biological treatment of swine wastewater. Ciência e Tecnologia de Alimentos, 30(1), 173-178. http://dx.doi.org/10.1590/ S0101-20612010000100026.

Moreira, I. O., Passos, T. S., Chiapinni, C., Silveira, G. K., Souza, J. C. M., Coca-Vellarde, L. G., Delizad, R., \& Lima Araújo, K. G. (2012). Colour evaluation of a phycobiliprotein-rich extract obtained from Nostoc PCC9205 in acidic solutions and yogurt. Journal of the Science of Food and Agriculture, 92(3), 598-605.

Mundt, S., Kreitlow, S., Nowotny, A., \& Effmert, U. (2001). Biochemical and pharmacological investigations of selected cyanobacteria. International Journal of Hygiene and Environmental Health, 203(4), 327-334. http://dx.doi.org/10.1078/1438-4639-00045. PMid:11434213

Rodrigues, M. I., \& Iemma, A. F. (2009). Planejamento de experimentos e otimização de processos (2nd ed., pp. 358). Campinas: Cárita.

Rodrigues, M. S., Ferreira, L. S., Converti, A., Sato, S., \& Carvalho, J. C. M. (2010). Fed-batch cultivation of Arthrospira (Spirulina) platensis: potassium nitrate and ammonium chloride as simultaneous nitrogen sources. Bioresource Technology, 101(12), 4491-4498. http://dx.doi. org/10.1016/j.biortech.2010.01.054. PMid:20153635
Sassano, C. E. N., Gioielli, L. A., Almeida, K. A., Sato, S., Perego, P., Converti, A., \& Carvalho, J. C. M. (2007). Cultivation of Spirulina platensis by continuous process using ammonium chloride as nitrogen source. Biomass and Bioenergy, 31(8), 593-598. http:// dx.doi.org/10.1016/j.biombioe.2007.04.001.

Silva, A. F., Lourenço, S. O., \& Chaloub, R. M. (2009). Effects of nitrogen starvation on the photosynthetic physiology of a tropical marine microalga Rhodomonas sp. (Cryptophyceae). Aquatic Botany, 91(4), 291-297. http://dx.doi.org/10.1016/j.aquabot.2009.08.001.

Tagma, T., Hsissou, Y., Bouchaou, L., Bouragba, L., \& Boutaleb, S. (2009). Groundwater nitrate pollution in Souss-Massa basin (south-west Morocco). African Journal of Environmental Science and Technology, 3(10), 301-309.

Tarko, T., Duda-Chodak, A., \& Kobus, M. (2012). Influence of growth medium composition on synthesis of bioactive compounds and antioxidant properties of selected strains of Arthrospira cyanobacteria. Czech Journal of Food Sciences, 30(3), 258-267.

Yun, Y. S., \& Park, J. M. (1997). Development of gas recycling photobioreactor system for microalgal carbon dioxide fixation. Korean Journal of Chemical Engineering, 14(4), 297-300. http:// dx.doi.org/10.1007/BF02706827.

Zarrouk, C. (1966). Contributionà létuded une cyanophycée: influence de divers facteurs physiques et chimiques sur la croissance et photosynthese de Spirulina maxima Geitler (PhD Thesis). University of Paris, Paris.

Zeng, X., Danquah, M. K., Zhang, S., Zhang, X., Wu, M., Chen, X. D., Ng, I., Jing, K., \& Lu, Y. (2012). Autotrophic cultivation of Spirulina platensis for $\mathrm{CO} 2$ fixation and phycocyanin production. Chemical Engineering Journal, 183, 192-197. http://dx.doi.org/10.1016/j. cej.2011.12.062. 